\title{
DICOTOMIA NATUREZA E CULTURA E SEUS REFLEXOS NAS ESTRUTURAS DE PARENTESCO ${ }^{1}$
}

\author{
Marcos Renato de Melo Freitas ${ }^{2}$
}

- Enviado em 15/04/2016

- Aprovado em 20/05/2016

\section{RESUMO}

Por sua relevância para a Antropologia, debates em torno da relação natureza-cultura, além de recorrentes, se encontram presentes no âmbito dessa ciência desde muito. Contudo, com o desenvolvimento de estudos etnográficos, importantes antropólogos passaram a refutar a dicotomia entre natureza e cultura, dentre estes, Claude Lévi-Strauss, que atribuiu esse dualismo à criação artificial de cultura. Este autor adotou a posição em comento como método, permitindo-lhe uma fecunda análise da realidade. Em seguida, surgiram as contundentes críticas de Philippe Descola e Bruno Latour, sendo este o responsável por destrinchar o mecanismo por trás da máquina purificadora, importante artifício para o afastamento dos fatos naturais dos culturais. Não alheia à superação desse paradigma dualista, as estruturas de parentesco também sofreram mudanças em suas bases, o que acaba por implicar alterações em relações até então tomadas como certas.

Palavras-chave: Paradigma dualista. Natureza e cultura. Estruturas de parentesco.

\section{INTRODUÇÃO}

O presente trabalho abordará a relação entre natureza e cultura dentro dos estudos antropológicos. Mais especificamente, nele se debaterá, além da origem da dicotomia entre ambos

\footnotetext{
${ }^{1}$ Uma versão preliminar desse trabalho foi apresentada no GT1: INSTITUIÇÕES E PODER: PARENTESCOS E GENEALOGIAS do VII Seminário Nacional de Sociologia e Política da UFPR realizado de 11 a 13 de maio de 2016 em Curitiba.
}

${ }^{2}$ Especialista em Direito Civil e Processual Civil pelo Instituto Paranaense de Ensino. Mestrando em Ciências Sociais pela Universidade Estadual de Maringá; Professor do Curso de Direito da Faculdade Maringá; E-mail: marcosrenato_freitas@hotmail.com. 
os conceitos, a superação dessa oposição natureza-cultura a partir da contribuição de grandes autores da Antropologia, como Claude Lévi-Strauss, Philippe Descola e Bruno Latour.

Nessa senda, buscar-se-á, sobretudo, investigar se existe, de fato, referida dicotomia, ao que já se traz, como hipótese básica, sua inocorrência, sem perder de vista que os debates em torno da separação entre os mundos natural e cultural é parte constituinte da própria Antropologia (JACQUES, 2010).

Na linha desse debate, procurar-se-á ainda averiguar qual o impacto da alteração no modo de se conceber o liame entre natureza e cultura nas estruturas de parentesco, supondo-se, de partida, que estas (estruturas) igualmente sofreram modificações na medida em que se verifica a falência do paradigma dualista.

\section{A ORIGEM DA DICOTOMIA NATUREZA-CULTURA}

O debate em torno da relação entre natureza e cultura é um dentre aqueles que se alonga por séculos na ciência, sendo que, ao longo do lapso transcorrido até então, muitas propostas para a solução do impasse já foram lançadas, sem que se chegasse, porém, a um consenso. Aliás, parte dessa divergência pode ser atribuída à própria variabilidade do significado que se conferiu a esses termos ao longo da história do pensamento humano.

Nesse sentido, o mundo natural, ora é tratado como realidade externa à consciência humana - a qual, por meio de nossos sentidos, se apresenta como fonte de nossas ideias -, ora como produto dessa mesma consciência, "que constitui o mundo exterior" - " "não existe uma Natureza em si', mas apenas uma 'Natureza pensada"” (JACQUES, 2010: 9).

Porém, antes de se chegar a tal dinamismo daquilo que percebemos por natureza, foi necessária a própria extração dessa ideia do arcabouço componente do pensamento humano. É a Aristóteles que se credita a primeira diferenciação entre os domínios da natureza e do humano: "A natureza passa a constituir uma ordem objetiva 'coerente e submetida a leis', no que difere da ordem humana" (JACQUES, 2010: 9).

Com tal contribuição aristotélica, o mundo passou a ser encarado a partir de duas ordens ontológicas distintas: uma objetiva, referente às ciências, e a outra, subjetiva. Dessa distinção, exsurgiu a contraposição, nas ciências, entre racionalismo e empirismos, correntes estas que fundam, respectivamente, nas supracitadas concepções do que seja o natural (JACQUES, 2010). 
Do mesmo modo, o termo "cultura" recebeu diferentes significados desde seu primeiro uso entre os romanos. Do verbo latino colere (traduzido ao português como "trabalhar na terra"), a palavra cultura se remete justamente ao campo da produção humana, sendo que, já na antiga sociedade romana, essa "produção" também era associada ao desenvolvimento de certas faculdades do espírito. Nesse sentido, Cícero, no século I a.C., já se valia da expressa cultura mentis (“cultivo da mente") para se referir à filosofia (PINO, 2005: 69).

Com a égide do pensamento Iluminista (século XVIII), o vocábulo cultura passou a designar o refinamento do espírito, mediante o cultivo de certas qualidades apreciadas pela sociedade da época. E foi somente com o surgimento de novos ramos científicos, como a sociologia e a antropologia, na segunda metade do século XIX, que cultura passou a significar o conjunto de bens materiais e espirituais dos diferentes povos, compreendidos aí os mitos, conhecimento, tradições, técnicas, etc (PINO, 2005: 70).

Apesar das diversas significações atribuídas ao termo em debate, Pino aduz que do conceito de cultura estão excluídos os aspectos do ser humano que "são inatos ou determinados pela genética. Em outros termos, natureza e cultura representam campos distintos que se contrapõem, sendo este último o definidor da especificidade do humano" (PINO, 2005: 71).

Do exposto, constata-se que a dicotomia entre o natural e o cultural se inicia com a própria segregação do domínio natural do universo compreendido pelo domínio do humano (leia-se, do cultural). Não obstante se originar com Aristóteles, é no Iluminismo, principalmente com René Descartes, que a contraposição se intensifica.

Segundo o pensamento de Descartes, "ideias e coisas são concebidas como universos a parte, corpo e alma como substâncias distintas e de essências opostas" (JACQUES, 2010: 7). E, conforme indica Philippe Descola (2011), a dicotomia em debate é justamente o fruto dessa visão metafísica da realidade proposta por este filósofo iluminista e por todo o racionalismo francês.

Dito isso, a dicotomia entre natureza e cultura pode ser entendida enquanto "contraposição do 'universal e particular, objetivo e subjetivo, físico e moral, fato e valor, dado e instituído, necessidade e espontaneidade, imanência e transcendência, corpo e espírito, animalidade e humanidade"" (JACQUES, 2010: 10), sendo precisamente tais distinções os alvos de crítica e de superação por grandes pensadores atuais da Antropologia.

Porém, previamente à análise da contribuição desses antropólogos, cumpre abordar em que estágio a discussão sobre a distinção entre o natural e o cultural se iniciou na Antropologia, no século XIX, e de que forma os novos cientistas desse novo campo de conhecimento lidaram com ela desde no início. 


\section{A ABORDAGEM ANTROPOLÓGICA DA RELAÇÃO NATUREZA-CULTURA}

Como exposto alhures, o nexo entre natureza e cultura é antigo objeto de debate, observando-se registros dessa discussão desde a Grécia Antiga, inclusive com Platão. Atravessando os séculos, tal discussão reencontra campo fértil na Idade Moderna, mais especialmente entre os teóricos "contratualistas".

Embora divirjam quanto à natureza do "contrato" e quanto ao próprio modo de se entender o hipotético "estado de natureza", os teóricos políticos "contratualistas" convergem todos quanto à crença na necessidade da passagem de um estado natural e selvagem para outro, cultural e civilizado, mediante um ato volitivo e racional (PINO, 2005: 71-72). Disso verifica-se a presença marcante da dicotomia natureza-cultura em suas obras que se constitui, inclusive, premissa básica para o desenvolvimento de suas teorias.

Mais recentemente, no período contemporâneo, a discussão em torno dessa dicotomia ganhou amplo espaço nas novas ciências, sobretudo na Antropologia, que "tardou" a surgir. Não obstante a humanidade, ao longo de toda sua história, tenha tentado encontrar respostas a suas origens, às tradições e às diferenças entre os diversos grupos, só foi possível uma verdadeira ciência em torno do homem e do que lhe é próprio - a Antropologia - a partir do acúmulo de informações sobre diversos povos, verificado desde o século XV (PINO, 2005: 78-79).

No liminar dessa novel ciência, a tensão entre duas correntes filosóficas marcaram a Antropologia quanto à discussão sobre os limites entre natureza e cultura: por um lado, o intelectualismo, ou racionalismo, e, pelo outro, o empirismo, ligado ao realismo. Tais correntes buscam descobrir, respectivamente, a fonte do conhecimento humano no espírito (razão) ou na experiência. (JACQUES, 2010: 7).

Nesse passo, influenciada pela concepção newtoniana (e Iluminista) de que todos os processos são regidos por leis eternas e universais, permanecendo em perfeita harmonia, a Antropologia, no início, cuidava não apenas da classificação das diferentes culturas observadas, mas também do estudo das fases pelas quais passariam os diversos povos, tudo sob o crivo de uma visão linear da história (PINO, 2005: 79).

A esse respeito, esclarece Clifford Geertz que:

A perspectiva iluminista do homem era, naturalmente, a de que ele constituía uma só peça com a natureza e partilhava da uniformidade geral de composição que a ciência natural havia descoberto sob o incitamento de Bacon e a orientação de Newton. Resumindo, há uma natureza humana tão regularmente organizada, tão perfeitamente invariante e tão maravilhosamente simples como o universo de Newton. Algumas de suas leis talvez sejam 
diferentes, mas existem leis; parte da sua imutabilidade talvez seja obscurecida pelas armadilhas da moda local, mas ela é imutável (GEERTZ, 2008: 25).

Porém, com a publicação de "A Origem das Espécies", de Charles Darwin, a visão perene e harmônica forjada por Newton acabou minada diante das ideias evolucionistas. Como reflexo disso, surgiram obras como "Crítica da Política Econômica", de Karl Marx e Friedrich Engels, que apontavam o modo de produção como o responsável pela evolução histórica das sociedades (PINO, 2005: 80). Ainda, a respeito da influência das ideias de Darwin na Antropologia, Nuernberg e Zanella comentam que:

A ideia de evolução subjacente ao darwinismo, por conseguinte, acabou por levar os antropólogos à distinção etnocêntrica entre sociedades "primitivas" e "avançadas", como se as diferenças entre elas revelassem indícios dos progressos da espécie humana nos modos de adaptação, através do aprimoramento da cultura. [...] Não obstante, é preciso destacar que, ainda que a cultura tenha, em função das ideias de Darwin, emergido como categoria determinante da conduta humana e das trocas sociais dos grupos investigados pelos etnólogos, ela permanece sendo tomada por uma parte dos antropólogos como uma decorrência de necessidades naturais. Ora tomada como produto da evidencia de sua praticidade (como em Lewis Henry Morgam), ora por sua utilidade (como em Franz Boas), a cultura é constantemente reduzida a algo subordinado ao biológico (NUENBERG; ZANELLA, 2003: 2).

No século XX, afinal, a antropologia se consolida enquanto ciência, apresentando duas grandes vertentes à época: a antropologia física e a antropologia cultural, interessando, para o momento, esta corrente.

No início, a antropologia cultural desenvolvia seus trabalhos sob a premissa de que existia tanto uma unidade biológica da natureza humana quanto uma igualdade natural dos homens, o que implicava na minimização das diferenças e especificidades existentes entre as culturas observadas. Num segundo momento, essa vertente assumiu postura diversa, ao internalizar como princípio a diversidade cultural dos povos, que passou a ser muito mais determinante de sua história do que qualquer unidade biológica (PINO, 2005: 80).

Sobre tais vieses adotados pela antropologia cultural, Angel Pino observa que:

Tudo indica que, nessas duas concepções do homem e das sociedades próprias da antropologia nos seus começos, o grande desafio que se colocava à nova ciência antropológica era conciliar a unidade biológica e a diversidade cultural da espécie humana, ou seja, a importância da ação da natureza ou a importância da ação da história do homem; desafio que se acentua no mundo contemporâneo da era da globalização. (PINO, 2005: 80$81)$.

Enquanto no final do século XIX predomina o pensamento evolucionista na antropologia, com a proximidade da Segunda Guerra Mundial, o enfoque dos antropólogos passou a ser a história 
cultural, que logo após foi superada por duas perspectivas teóricas: o funcionalismo, de Arnold R. Radcliffe-Brown e Bronislaw Malinowski, e o estruturalismo, de Claude Lévi-Strauss.

Em virtude disso, se o princípio que norteava os trabalhos antropológicos no fim do século XIX era o da existência de uma natureza humana universal, cujas diferenças observadas entre os povos são atribuídas aos diferentes níveis de desenvolvimento, o princípio da multiplicidade de formas culturais e da importância das características culturais de cada povo dá origem, no século $\mathrm{XX}$, a novas interrogações sobre a natureza do homem que nem sempre encontram a resposta adequada (PINO, 2005: 84).

Com isso, observa-se a progressiva suplantação da dicotomia entre os domínios do natural e do cultural, já que os teóricos que perfilharam a discussão em torno dessa distinção procuravam encontrar algo propriamente humano, centrando suas explicações ora em caracteres genéticos e instintivos, ora em características decorrentes da influência do meio ambiente ou da cultura (NUERNBERG; ZANELLA, 2003). Em suma, o paradigma dualista, de caráter "naturalizante", exigia do cientista a descoberta de uma natureza única para seu objeto de estudo: o homem (VELDEN; BADIE, 2011).

\section{SUPERAÇÃO DA OPOSIÇÃO ENTRE O NATURAL E O CULTURAL}

Com o desenvolvimento de novos estudos, o paradigma dualista passou a ser alvo de questionamentos entre os intelectuais da Antropologia, na medida em que a divisão entre natureza e cultura começou a se mostrar inadequada à abordagem dos novos casos submetidos às pesquisas antropológicas.

Como exemplo disso, o pensamento ameríndio é digno de nota, pois, diversamente da concepção moderno-ocidental, não entende a natureza e a cultura como campos ontológicos distintos, mas como "pontos de vista". Assim sendo, "Se para os ocidentais, a continuidade entre natureza e cultura, 'nós' e 'outros', está no corpo, lugar da animalidade, regido pelas leis da biologia e da física, para os ameríndios é o espírito que integra" (JACQUES, 2010: 11).

Dito isso, Tatyana de Alencar Jacques ressalta que, embora Viveiros de Castro antropólogo que estudou sobredito pensamento dos povos tribais da América - não tenha se distanciado da oposição entre o natural e o cultural, ao evidenciar o multinaturalismo e o uniculturalismo dos ameríndios, "a separação paradigmática do mundo entre natureza e cultura não 
é adequada para apreender o que [...] [Viveiros de Castro] chama de perspectivismo ameríndio." (JACQUES, 2010: 11).

No mesmo sentido, mas sem abandonar a crença em algo genuinamente humano, Clifford Geertz (2008: 26) alerta para a ilogicidade da ideia de que a grande diversidade entre os povos, em termos de crenças, valores, costumes e instituições, ao longo do tempo e dos lugares, não serve para definir a natureza do homem, sendo "meros acréscimos, até mesmo distorções", do que lhe é verdadeiramente constitutivo, essencial.

De encontro a tal concepção, Geertz (2008: 26) problematiza a inexistência de uma natureza humana imutável, insuscetível de variações conforme o tempo, o lugar e quaisquer outras circunstâncias, mesmo que passageiras, como algumas modas e opiniões, aduzindo, assim, à ilusão de uma tal "imagem perene do homem".

Por isso, certa de que inexistem homens "não-modificados pelos costumes de lugares particulares", a Antropologia, segundo Geertz (2008: 27), aponta como falsificação do que é humano qualquer tentativa de se distinguir "o que é natural, universal e constante no homem, e o que é convencional, local e variável". Para elucidar esse ponto, utiliza-se ele do caso do "transe balinês". Ao longo desse transe, os balineses executam "atividades espetaculares", muitas vezes excêntricas ou mesmo repugnantes para o padrão moderno-ocidental, e, apesar de não se recordarem de nada ao retornarem à sobriedade, satisfaziam-se com a experiência havida. Com esse caso em vista, Geertz provoca a seguinte reflexão em torno da existência da divisão entre o que é natural e o que é cultural no homem:

O que se pode aprender sobre a natureza humana a partir dessa espécie de coisa e das milhares de coisas igualmente peculiares que os antropólogos descobrem, investigam e descrevem? Que os balineses são espécies peculiares de seres, marcianos dos Mares do Sul? Que eles são iguais a nós, no fundo, mas com alguns costumes peculiares, verdadeiramente incidentais, que não nos agradam? Que eles são mais dotados inatamente ou mais instintivamente dirigidos em certas direções que outros? Ou que a natureza humana não existe e que os homens são pura e simplesmente o que a sua cultura faz deles? (GEERTZ, $2008: 27$ ).

Diante dessa problematização, o ex-professor da Universidade de Princeton, EUA, aponta como caminhou para a elaboração de um conceito de humanidade em que se insiram a cultura e a variabilidade cultural. O autor afirma que, embora um fenômeno cultural não seja "empiricamente universal", não deve ser rejeitado de plano, afinal: "O ponto crítico em ciência não é se os fenômenos são empiricamente comuns [...], mas se eles podem ser levados a revelar os processos naturais duradouros subjacentes neles" (GEERTZ, 2008: 27-32). 
Partindo das premissas de que a cultura é melhor compreendida como "conjunto de mecanismos de controle" e que o homem é totalmente dependente desses mecanismos para orientar seu comportamento, Geertz conclui que a natureza humana não prescinde da cultura. Categoricamente, afirma que:

Os homens sem cultura não seriam os selvagens inteligentes de Lord of the Flies, de Golding, atirados à sabedoria cruel dos seus instintos animais; nem seriam eles os bons selvagens do primitivismo iluminista, ou até mesmo, como a antropologia insinua, os macacos intrinsecamente talentosos que, por algum motivo, deixaram de se encontrar. Eles seriam monstruosidades incontroláveis, com muito poucos instintos úteis, menos sentimentos reconhecíveis e nenhum intelecto: verdadeiros casos psiquiátricos. (GEERTZ, 2008: 32-35).

Do mesmo modo, Tim Ingold busca superar a dicotomia entre natureza e cultura. Em "The perception of the environment", o autor efetiva a análise de seus objetos levando sempre em conta o ambiente do qual participam. E, muito além de propor um ambiente passivo à ação humana, Ingold adota em sua obra um "paradigma ecológico", segundo o qual todos os seres (humanos e não humanos) “[...] se movem junto com o 'meio' em que vivem [...]”, não vivendo “nele", senão vivendo "com" ele (VELDEN; BADIE, 2011).

Por isso, refuta de forma veemente o neodarwinismo, tendo em vista que lhe é errônea qualquer ideia de evolução associada à mutação, à recombinação, enfim, à "seleção natural". Para Ingold, evolução evoca a ideia de "processo vital", de "relações mutuamente condicionantes" (PITROU, 2015).

Ainda de acordo com o mesmo autor, os "seres humanos podem ser pensados 'em termos não do que são, mas do que fazem", na medida em que contribuem à dinâmica "evolutiva" dos organismos; dinâmica essa para a qual concorrem todas as formas de vida, bem como o próprio ambiente. Por isso, sua teoria da evolução "[...] enfatiza a porosidade das fronteiras entre humano e não humano, organismo e ambiente, ao se assumir uma visão (eco) sistêmica, a única visão que permite que se afirme legitimamente que "o domínio do social e o biológico são um só" (PITROU, 2015: 183).

Já Philippe Descola, apresenta o histórico da relação entre natureza e cultura, expondo ainda, nessa obra, os acontecimentos (fatores) que permitiram repensar o paradigma dualista - que, segundo ele, não é algo evidente em outras épocas, senão na moderna sociedade ocidental (DESCOLA, 2011).

Para sua tese doutoral (La nature domestique), orientada por Claude Lévi-Strauss, Descola promoveu um amplo estudo etnográfico entre os Achuar, da Amazônia. Em sua tese, o autor propôs uma abordagem sistemática das relações desse grupo tribal com a natureza, que, entre os Achuar, 
“[...] era, antes, tida por sujeito participante das relações sociais". Aliás, a noção de "sujeito" dentro da cosmologia desse povo pressupõe que todos os entes, humanos e não-humanos, são dotados de alma (wakan) (SÁ JÚNIOR, 2014).

Com base nessa cosmologia dos Achuar, provada de forma semelhante entre os Makuna da Colômbia e os índios da região subártica do Canadá, Descola afirma que os domínios do natural e do cultural não se encontram absolutamente isolados, mas, apresentam continuidades entre si (SÁ JÚNIOR, 2014). Por isso, é possível afirmar que:

A sutileza como o humano e o natural se interpenetram é reveladora. Assim, sempre há possibilidade dos humanos se transformarem em animais e os animais em humanos. $\mathrm{O}$ que mesuramos destes escritos é que as "cosmologias" indígenas não atuam no sentido de opor espécies e/ou espaços, humano de um lado e não humano do outro. A ação humana é criadora de inter-relações com natural. E por intermédio dessas interrelações espaços são construídos. E se construir sempre tem como meta o habitar, os Achuar habitam de forma peculiar o mundo que é elaborado dentro de suas cosmologias (MARTINS, 2010: 12).

Bruno Latour (1994: 7-17) ataca a oposição entre natureza e cultura ao revelar o mecanismo responsável por forjar a concepção dualista. Segundo ele, o conjunto de práticas "modernas", denominadas "purificação" e "tradução", implica na perpetuação de tal dicotomia, embora enseje, ao mesmo tempo, a proliferação de híbridos natural-culturais, que operam livremente em ambos os domínios, e que, afinal, se encontram apenas ideologicamente separados.

Por conseguinte à denúncia dos mecanismos de operação da "máquina purificadora", logrou ele superar a visão de que a ciência, ao permitir o desenvolvimento dos meios de dominação do meio em que se encontra o homem, o distanciaria da natureza. A tese é revista em favor de uma concepção do todo da realidade (de "redes"), em que não apenas o social, mas, sobretudo o natural, são frutos da ação orientada pelas técnicas e tecnologias.

Assim, denunciado o modus operandi da "máquina purificadora", ou seja, a "[...] separação radical entre a representação das coisas em laboratório (ciência) e a representação dos cidadãos do contrato social (política)", mas, ao mesmo tempo, evidenciada a presença concomitante dos "híbridos", Latour demonstra "[...] a existência de um tecido inteiriço entre natureza e cultura, fatiado arbitrariamente pelas diferentes culturas" (JACQUES, 2010: 10). ${ }^{3}$

\footnotetext{
${ }^{3}$ Não obstante as contribuições de Latour e todo seu esforço pela superação do paradigma dualista, cumpre anotar a contundente crítica de Tatyana de Alencar Jacques (2010) às ideias do intelectual francês: "É interessante ressaltar, nesse sentido, que a própria noção de híbrido de Latour (1994) parece ser outro desses paradoxos, pois a ideia de híbrido só faz sentido a partir do momento em que deixamos de considerar a existência de um tecido inteiriço entre natureza e cultura para considerar rupturas entre esses dois domínios, e elementos compostos a partir dessa diferenciação. Na perspectiva de Latour, jamais teríamos sido modernos por sermos incapazes de eliminar os híbridos. No entanto, talvez sejamos sim, bastante modernos, por sermos capazes de concebê-los enquanto tais e não enquanto 
Por fim, embora tenha sido acusado pela antropologia anglo-saxônica de ser defensor do dualismo natureza-cultura (DESCOLA, 2011), Claude Lévi-Strauss refuta, a seu modo, essa separação, ao afirmar que ela não é algo inerente à ordem do mundo, mas,

[...] uma criação artificial da cultura, uma obra defensiva que esta última [cultura] teria cavado em redor de si porque não se sentia capaz de afirmar sua existência e originalidade a não ser cortando todas as passagens adequadas a demonstrar sua conivência originária comas outras manifestações da vida (LÉVI-STRAUSS, 1982: 26).

Não obstante, vale-se o autor de tal oposição enquanto instrumento de análise, o que lhe permite redefinir a própria relação entre natureza e cultura, não mais enrijecida na necessária unicidade daquela em contraposição à pluralidade desta (VELDEN; BADIE, 2011). Apesar de "altamente produtiva" essa opção de Lévi-Strauss, traz ela a perplexidade de tornar árdua a tarefa de se interpretar sua obra. Desse modo, e conforme afirma Descola:

Ninguém ignora o papel crucial que tem na obra de Claude Lévi-Strauss a oposição contrastiva entre natureza e cultura: ele a utiliza em contextos tão diversos e com finalidades tão numerosas que, para muitos, ela chegou a encarnar uma das características de sua maneira de pensar (DESCOLA, 2011: 35).

Para o fundador da Antropologia estruturalista, toda vida social é regida por dois determinismos que se completam e atuam concomitantemente: o determinismo mental - que "[...] reflete as exigências inerentes ao funcionamento do espírito e se manifesta sempre idêntico, independentemente das diferenças entre os meios" - e o determinismo do meio - que, "[...] de tipo tecnoeconômico, impõe ao pensamento coerções resultantes da relação que a sociedade mantém com um meio particular" (DESCOLA, 2011: 37).

Assim, ao informar esse diálogo entre os domínios do natural e do cultural, Claude LéviStrauss afirma que "[...] a cultura não pode ser considerada nem simplesmente justaposta nem simplesmente superposta à vida. Em certo sentido substitui-se à vida, e em outro sentido utiliza-a e a transforma para realizar uma síntese de nova ordem" (LÉVI-STRAUSS, 1982: 42).

Todavia, em que pese defender a igualdade entre ambos os determinismos, resta claro que na obra de Lévi-Strauss o determinismo mental tem primazia, servindo o meio físico apenas de fornecedor da matéria da qual se abastece o pensamento mítico. Por esse motivo, Descola confirma o acerto da crítica dirigida a Lévi-Strauss sobre seu desinteresse pela "[...] incidência dos fatores ecológicos sobre todos esses aspectos da vida social que não podem ser considerados produtos da atividade simbólica” (DESCOLA, 2011: 38).

continuidade e indistinção. Com isso, mesmo Latour parece não conseguir purificar-se da purificação e prova do seu próprio veneno, jamais deixando de ser moderno." 
Como resposta à objeção de dualismo em sua obra, Lévi-Strauss aduz que as estruturas captadas pelo sistema nervoso, por meio de processos binários de codificação e decodificação, existiriam previamente na própria natureza. Isto é, “A estrutura não seria, portanto, puro produto do intelecto pondo livremente em forma uma realidade plástica; [pois] o espírito não cessa de trabalhar estruturalmente informações que ele recebe já estruturadas pela sensibilidade" (DESCOLA, 2011: 39).

Assim, Lévi-Strauss remete ao domínio da natureza o que se diria apenas próprio do espírito, afastando, por consequência, eventual pecha de dualista que lhe poderiam dirigir. Afinal, conforme revela Philippe Descola (2011), Lévi-Strauss, desde cedo, percebera que a oposição natureza-cultura, apesar de produtiva enquanto instrumento de análise, não corresponde à realidade que a Antropologia se dedica a estudar.

\section{O DUALISMO NATUREZA-CULTURA E SEUS REFLEXOS NAS ESTRUTURAS DE PARENTESCO}

Por ocupar espaço central na Antropologia, o debate em torno da relação entre os domínios do natural e do cultural não poderia deixar de refletir seus desdobramentos nos diversos âmbitos de pesquisa dessa ciência, como é o caso dos estudos sobre as estruturas de parentesco.

Nesse sentido, segundo a antropóloga britânica Marilyn Strathern (1992: 174), o colapso do distanciamento forjado (abstratamente) entre natureza e cultura certamente impacta no modo de se imaginar as relações de parentesco, ao se alterarem sensivelmente as estruturas (ora existentes) que informam as similaridades e as diferenças estabelecidas nas relações atuais, as quais são, hodiernamente, tomadas como certas ("naturais").

Janet Carsten (2004: 186-187), por seu turno, explica o porquê do impacto: não apenas as noções ocidentais, mas também as próprias definições antropológicas são informadas por uma série de dicotomias, tais como natureza e cultura, biológico e social etc. Nesse passo, esclarece ela ainda que:

There is no doubt that an opposition between nature and culture has been at the heart of Euro-American ideas for several hundred years, and it may well constitute the local manifestation of a distinction that is perhaps universally made between what is "given" and what is "made" (CARSTEN, 2004: 188) .

\footnotetext{
4 Tradução livre: "Não há dúvidas de que uma oposição entre natureza e cultura está no coração das ideias EuroAmericanas há muitos anos, e isso pode constituir a manifestação local da distinção talvez universal feita entre o que é 'dado' e o que é 'construído'".
} 
Na sequência, Carsten, reportando-se à proposta de Latour de se abandonar a divisão entre natureza e cultura, concorda com Marilyn Strathern quanto à redefinição do parentesco, eis que não apenas esse conceito passa a não assumir uma relação particular com ou um limite entre natureza e cultura, mas também por colocar no mesmo sistema analítico as culturas Ocidentais e as nãoOcidentais.

Como consequência, expõe Carsten (2004: 189) que:

We can then no longer sustain the notion that whereas "they" have kinship, "we" have families, just as we can not assume that, whereas in the West what is social and what is biological are firmly and clearly separated in opposed domains, in non-Western cultures they are inextricably mixed up (tradução livre) (CARSTEN, 2004: 188) .

Apesar de aplaudir a proposta de Latour, a autora de After Kinship propõe, como proveitoso objeto de análise antropológica sobre o parentesco, as distinções no modo de se conceber entre os diversos povos o que é dado pela natureza e o que é "construído" pelo homem, o que é biológico e o que é social, a fim de se angariar uma nova forma de compreensão das estruturas em comento (CARSTEN, 2004: 189).

Não obstante tal proposta, cumpre frisar que a superação da dicotomia entre os domínios do natural e do cultural permite, afinal, não apenas afastar a noção de parentesco calcada nos estritos liames genéticos (biológicos), mas também ampliar os horizontes da concepção moderno-ocidental sobre o que é família e, portanto, sobre quem são os familiares, os parentes.

Nessa toada, Strathern (1992: 175), adentra a problemática surgida, nos anos 1990, para as relações de parentesco calcadas na dicotomia em tela graças ao desenvolvimento de novas técnicas de reprodução, mais especificamente daqueles procedimentos que envolvem a gestação ou o uso de gametas de pessoas que não compõem o núcleo familiar que deseja a concepção de uma criança.

Diante dessa problemática, a referida antropóloga estabelece a ressignificação do conceito de parentalidade: "[...] the parents will be those who planned and wished for a child to be born to them" ". Com isso, a relação paterno e materno-filial não mais se apresenta atrelada aos "laços de sangue", à descendência genética, mas ao efetivo exercício dessa paternidade e/ou maternidade (STRATHERN, 1992: 178).

\footnotetext{
5 Tradução livre: "Não podemos mais sustentar a noção de que enquanto "eles" têm parentesco, "nós" temos família, assim como não podemos supor que, enquanto no Ocidente o que é social e o que é biológico são firme e claramente separados em domínios opostos, em culturas não-Ocidentais eles estão indissociavelmente misturados".
}

${ }^{6}$ Tradução livre: "Os pais são aqueles que planejaram e desejaram que uma criança fosse nascida deles". 
Por isso, caso a espécie que se obrigue judicialmente à descoberta de um vínculo genético quando o mesmo não é quisto, resulta que, muitas das vezes, o próprio investigando já se encontra plenamente realizado em sua família "social" (adotiva) ou mesmo em alguma na qual não haja a presença de um dos genitores biológicos, como é o caso das famílias monoparentais.

Dito isso, evidencia-se a insistência no dualismo natureza-cultura - cuja existência sempre foi artificial. Isso se comprova por meio de decisões como a da Suprema Corte da Argentina, a qual submeteu material genético de um menino de uma família não biológica a exame, mesmo sem o consentimento deles, para se saber se seria o filho de algum perseguido político da ditadura militar havida naquele país nos anos 1970 (PITROU, 2015), ou mesmo pelo Projeto Pai Presente, do CNJ, cujo fundamento é a crença de que as crianças registradas apenas com o nome materno precisam conhecer e conviver com aqueles que concorreram para sua concepção, apesar do patente desinteresse desses "pais" biológicos.

\section{CONSIDERAÇÕES FINAIS}

A dicotomia entre natureza e cultura sempre pautou intensas discussões na Antropologia, não havendo, afinal, consenso sobre o assunto. Não obstante, célebres antropólogos se dedicaram a refutar tal oposição, merecendo destaque as contribuições de Lévi-Strauss, que, embora empregasse a dualidade em sua obra, foi um dos responsáveis por evidenciar que a cosmologia dos povos tribais não se compatibiliza com a distinção entre os domínios do natural e do cultural. Ainda destacam-se Geertz e seu esforço por encontrar uma natureza universal do homem nas particularidades culturais, da teoria evolutiva de Ingold em que organismos (humanos e não-humanos) e ambiente influenciam um no outro, de Descola e a cosmologia de povos tribais, de Latour e a revelação da "máquina purificadora”, dos híbridos e de uma tessitura inteiriça entre natureza e cultura.

E, enquanto parte importante da Antropologia, os estudos sobre as estruturas de parentesco sofreram substanciais reformulações com o peso da crítica à oposição entre natureza e cultura. Nesse sentido, a própria noção de parentalidade se alterou, ao se fulminar com sua estrita definição anterior, que era pautada apenas nos liames biológicos (genéticos) estabelecidos entre pai e/ou mãe e filho. Diante desse novo quadro, algumas políticas ou decisões oficiais se apresentam ilegítimas, por desconsiderarem as novas nuances das relações de parentesco. 


\section{REFERÊNCIAS}

CARSTEN, Janet. After kinship. Cambridge: Cambridge University Press, 2004.

DESCOLA, Philippe. As duas naturezas de Lévi-Strauss. In: Revista Sociologia e Antropologia, v. 1, n. 2, nov. 2011. Disponível em: <http://revistappgsa.ifcs.ufrj.br/wp-content/uploads/2015/03/2ano1v2_artigo_philippe-descola.pdf >. Acesso em: 21 set. 2015.

GEERTZ, Clifford. A interpretação das culturas. 1. ed. Rio de Janeiro: LTC, 2008.

INGOLD, Tim. Humanity and animality. In: . (Ed.). Companion encyclopedia of anthropology. Londres: Routledge, 1994.

JACQUES, Tatyana de Alencar. Sobre o impacto da dicotomia natureza e cultura na Antropologia. Antropologia em Primeira Mão, v. 123, 2010. Disponível em:

<http://apm.ufsc.br/files/2011/06/123.-JACQUES.-Tatyana-de-Alencar.-Sobre-o-impacto-dadicotomia-natureza-e-cultura-na-Antropologia.-2010.pdf>. Acesso em: 21 set. 2015.

LATOUR, Bruno. Jamais fomos modernos: ensaio de antropologia simétrica. Tradução de Carlos Irineu da Costa. Rio de Janeiro: 34, 1994.

LÉVI-STRAUSS, Claude. As estruturas elementares do parentesco. Tradução de Mariano Ferreira. Petrópolis: Vozes, 1982.

MARTINS, Geraldo Inácio. Existir como natureza, viver numa cultura: pensar e habitar com novas territorialidades. In: Geo UERJ, v. 2, n. 21, jan./jun. 2010. Disponível em: <http://www.epublicacoes.uerj.br/index.php/geouerj/article/viewFile/1478/1238>. Acesso em: 20 out. 2015.

NUERNBERG, Adriano Henrique; ZANELLA, Andréa Vieira. A relação natureza e cultura: o debate antropológico e as contribuições de Vygotski. In: Interação em Psicologia, Curitiba, v. 7, n. 2, 2003. Disponível em: 〈http://ojs.c3sl.ufpr.br/ojs/index.php/psicologia/article/view/3226>. Acesso em: 21 set. 2015.

PINO, Angel. As marcas do humano: às origens da constituição cultural da criança na perspectiva de Lev S. Vigotski. São Paulo: Cortez, 2005.

PITROU, Perig. Uma antropologia além de natureza e cultura? In: Mana, Rio de Janeiro, v. 21, n. 1, p. 181-194, abr. 2015. Disponível em:

<http://www.scielo.br/scielo.php?script=sci_arttext\&pid=S010493132015000100181\&lng=en\&nrm=iso>. Acesso em: 21 set. 2015.

SÁ JÚNIOR, Luiz César. Philipe Descola e a virada ontológica na antropologia. In: Revista Ilha, v. 16, n. 2, p. 7-36, ago./dez. 2014. Disponível em: <https://periodicos.

ufsc.br/index.php/ilha/article/viewFile/2175-8034.2014v16n2p7/29164>. Acesso em: 20 out. 2015.

STRATHERN, Marilyn. After nature: english kinship in the late twentieth century. Cambridge:

Cambridge University Press, 1992. 
VELDEN, Felipe Vander; BADIE, Marilyn Cebolla. A relação entre natureza e cultura em sua diversidade: percepções, classificações e práticas. In: Avá, Posadas, n. 19, dic. 2011. Disponível em: <http://www.scielo.org.ar/scielo.php?script=sci_arttext\&pid=S1851-

$16942011000200001 \& \operatorname{lng}=$ es\&nrm=iso>. Acesso em: 21 set. 2015.

\title{
DICHOTOMY NATURE AND CULTURE AND ITS CONSEQUENCES IN STRUCTURES OF RELATIONSHIP
}

\begin{abstract}
Due to its relevance to Anthropology, the debates around the relationship of nature and culture are recurrent and present in this science since long. The idea of opposition between both concepts prevailed by metaphysical influence, traced back to modern times. However, because of the development of ethnographic studies, important anthropologists began to refute the dichotomy between nature and culture, among them Claude Levi-Strauss, who attributed this dualism to the artificial creation of culture. The author adopted the opposition under discussion as a method, which allowed him a fruitful analysis of reality. He was followed by the categorical critics of Philippe Descola and Bruno Latour, and this one was responsible for solving the mechanism behind the purifying machine, as an important tool to separate the natural facts of cultural facts. Despite the overcome of the dualistic paradigm, the kinship structure also had some changes in their bases, which imply changes in the relationships that previously were thought to be certain.
\end{abstract}

Key-words: Dualistic paradigm. Nature and culture. Kinship structures. 